\title{
Diffuse palmoplantar keratoderma with painful fissures
}

INSERM

\section{Source}

INSERM. (1999). Orphanet: an online rare disease and orphan drug data base. Diffuse palmoplantar keratoderma with painful fissures. ORPHA:369999

Diffuse palmoplantar keratoderma with painful fissures is a rare, genetic, isolated palmoplantar keratoderma disorder characterized by non-epidermolytic, diffuse hyperkeratotic lesions affecting both the palms and the soles, associated with a tendency of painful fissuring. Contrary to the clinical findings, histologic examination reveals findings suggestive of keratosis palmoplantaris striata, with orthohyperkeratosis featuring widening of the intercellular spaces and disadhesion of keratocytes in the upper epidermal layers. 